\title{
Diagnosing giant cell tumor of the bone using positron emission tomography/computed tomography: A retrospective study of 20 patients from a single center
}

\author{
AIKEREMUJIANG MUHEREMU ${ }^{1,2}$, YUAN MA $^{1}$, ZHEN HUANG $^{2}$, \\ HUACHAO SHAN ${ }^{2}$, YUAN $\mathrm{LI}^{2}$ and XIAOHUI NIU ${ }^{2}$
}

${ }^{1}$ Department of Spine Surgery, Sixth Affiliated Hospital of Xinjiang Medical University, Ürümqi, Uygur Autonomous

Region 830011; ${ }^{2}$ Department of Orthopedic Oncology Surgery, Beijing Jishuitan Hospital, Beijing 100035, P.R. China

Received June 3, 2016; Accepted February 27, 2017

DOI: $10.3892 / 01.2017 .6379$

\begin{abstract}
The aim of the present study was to evaluate the sensitivity of positron emission tomography/computed tomography (PET/CT) in the diagnosis of giant cell tumor of the bone (GCTB) using the maximum standard uptake value (SUVmax), which indicates the metabolic rate of tissue. Patients diagnosed with pathologically confirmed GCTB between January 2006 and July 2015 were included in the study. Data from PET/CT scans and pathological and clinical reports for all patients were retrospectively reviewed. The SUVmax value from the PET/CT scan of each patient was retrieved and analyzed. A total of 20 patients $[12$ male and 8 female; age range, 12-45 years; mean age \pm standard deviation (SD), 33.5 \pm 15.7$]$ with complete PET/CT data and a pathologically and clinically confirmed diagnosis were examined. The SUVmax of GCTB was between 1.8 and 18.6, with a mean \pm SD of 9.2 \pm 3.8 . Although GCTB is not considered to be a malignant lesion, PET/CT scans of the tumors reveal high-grade malignant osseous sarcomas. It is, therefore, important not to mistake such lesions for osteosarcomas or metastatic malignancies of the bone.
\end{abstract}

\section{Introduction}

Giant cell tumor of the bone (GCTB) is a primary intramedullary bone tumor with variable growth potential (1). GCTB does not normally exhibit the invasive growth pattern of malignant sarcomas; however, patients often require a second or third surgical resection owing to recurrence and metastasis following inadequate surgical treatment by an inexperienced

Correspondence to: Dr Xiaohui Niu, Department of Orthopedic Oncology Surgery, Beijing Jishuitan Hospital, 31 Xin Jie Kou Dong Jie, Xicheng, Beijing 100035, P.R. China

E-mail: niuxiaohui@263.net

Key words: positron emission tomography/computed tomography, maximum standard uptake value, giant cell tumor of the bone orthopedic surgeon $(2,3)$. At the Department of Orthapedic Oncology Surgery, Beijing Jishuitan Hospital (Beijing, China), $>50 \%$ of patients with GCTB present with recurrent or metastatic lesions following surgical treatment at an orthopedic center not specialized in orthopedic oncology.

A diagnosis of GCTB is confirmed through analysis of the clinical, radiological and histopathological manifestation of the disease. Patients with GCTB often present with pain and swelling at the site of the lesion. Occasionally, a pathological fracture is the direct reason for the patients' attendance at the orthopedic clinic (Fig. 1) (4). X-ray and computed tomography (CT) scans may show eccentric lytic lesions with a cortical extension. Recently, with the increasing popularity of novel imaging techniques, including positron emission tomography (PET)/CT, the accuracy of bone tumor diagnosis has markedly improved (5). However, owing to the high cost of PET/CT for this supposedly benign tumor (and thus the reluctance of the clinician to order it) there are few studies concerning how GCTB manifests in PET/CT scans (this is particularly true in Asian countries). In the present study, the PET/CT scans from histologically confirmed GCTB patients treated in the Department of Orthopedic Oncology Surgery of Beijing Jishuitan Hospital were retrospectively reviewed to investigate the diagnostic value of PET/CT for patients with GCTB.

\section{Patients and methods}

Patient eligibility. The study was approved by the Ethical Committee of Beijing Jishuitan Hospital (Beijing, China). All patients enrolled in this study underwent PET/CT scans between January 2006 and July 2015 and were confirmed to have a pathological and clinical diagnosis of GCTB.

Demographic characteristics of included patients. Data from 20 patients (12 men and 8 women; mean age, $33.5 \pm 15.7$ years; age range, 12-45 years) with complete PET/CT scans and a pathologically and clinically confirmed diagnosis were analyzed.

${ }^{18} \mathrm{~F}$-fludeoxyglucose $\left({ }^{18} \mathrm{~F}-\mathrm{FDG}\right) \mathrm{PET} / \mathrm{CT}$ scanning. Prior to chemotherapy, patients underwent ${ }^{18} \mathrm{~F}$-FDG PET testing. 
These tests were performed using a PET/CT scanner, which was a combined full-ring PET scanner and spiral CT scanner. When the patient's blood glucose level reached $<11.1 \mathrm{mmol} / 1$ following a 6 -h fast, $400 \mathrm{ml}$ barium sulfate was administered, followed by an intravenous injection of $450 \mathrm{MBq}{ }^{18} \mathrm{~F}-\mathrm{FDG}$. PET and CT images were acquired from the base of the head to the middle of the thigh, with a wider range of observations taken if the tumor was located below the thigh.

Pathological examinations. Fine-needle and intraoperative biopsies were performed by senior attending surgeons and the chief of surgery, and examined by an experienced specialist from the Department of Pathology, who was provided with all patient information other than the results of the patient's PET/CT scan. The diagnosis was confirmed by observing the resected tumors or from the follow-up clinical and radiological materials of the patient. Once the pathological and clinical diagnosis was confirmed, the results were recorded and analyzed at the end of the study.

Statistical analysis. The SUVmax of each PET/CT scan was recorded and analyzed using SPSS 17.0 (SPSS, Inc., Chicago, IL, USA). The mean age and SUVmax were calculated and recorded as the mean \pm standard deviation $(\mathrm{SD})$.

\section{Results}

PET/CT scans detected 28 lesions on the 20 patients. The SUVmax of these lesions ranged between 1.8 and 18.6, and the mean SUVmax was 9.2 \pm 3.8 .

Of the 20 patients included in this study, 9 had never received any surgical or adjuvant therapies prior to the PET/CT scan. As prior therapy could have altered the avidity of tumor cells (thus affecting the SUVmax in PET/CT tests), data from those patients were analyzed separately, in addition to the overall analysis. The mean SUVmax of those 9 patients was 9.2 \pm 2.9 (range, 5.2-13.7). Although the mean SUVmax value was the same as for the 20 patients overall, the range of values and the SD were smaller.

The majority of GCTBs were located in the extremities (Fig. 2), but some spinal (Fig. 3) and pelvic (Fig. 4) lesions, in addition to several lung metastases (Fig. 5), were observed. To assess whether the PET/CT scans were affected by the location of GCTB, SUVmax values were also analyzed according to their source locations. The analysis revealed that the mean SUVmax of GCTB was higher in the pelvis and spine than the extremities, however, the difference was not significant (Table I).

\section{Discussion}

GCTB accounts for 5\% of primary skeletal tumors and $21 \%$ of benign bone tumors $(6,7)$. The tumor occurs primarily in the distal femur, proximal tibia and distal radius (8-12), with the incidence of GCTB in small bones being relatively rare (13). Diagnostic parameters and treatment measures of GCTB remain controversial among surgeons (14). In general, GCTB is metabolically benign and appears primarily at a single site; however, a considerable portion of patients present with GCTB in multiple locations. In the present study, 28 GCTB lesion

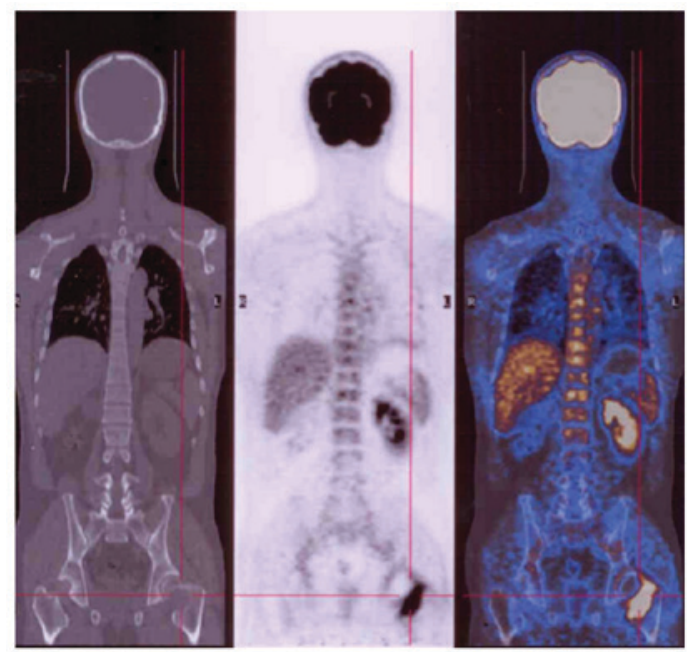

Figure 1. Images from (A) CT, (B) PET and (C) PET/CT from the coronal plane of a patient with a pathological fracture of the left femoral neck (indicated by the crosshair) caused by giant cell tumor of the bone. Maximum standard uptake value, 5.4. CT, computed tomography; PET, positron emission tomography.
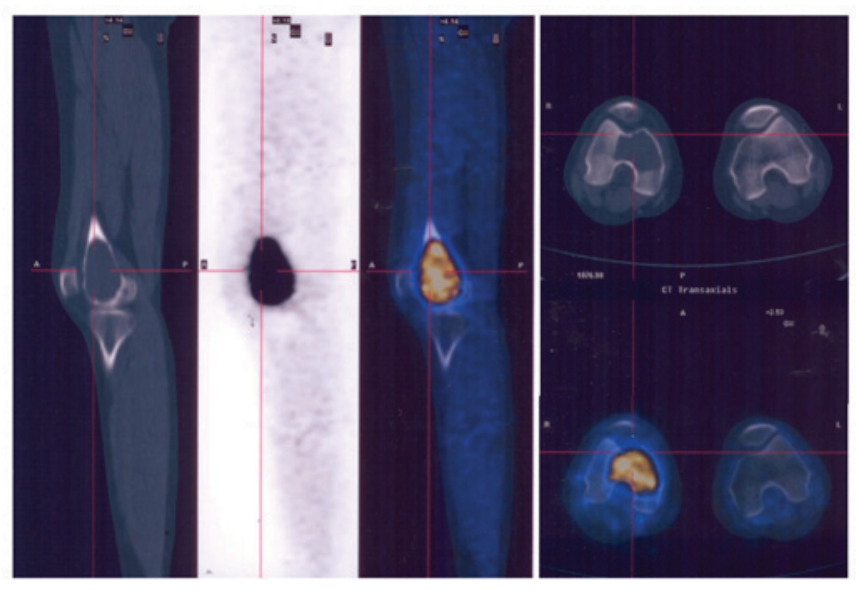

Figure 2. Images from (A) CT, (B) PET and (C) PET/CT from the sagittal plane, and images of (D) CT and (E) PET/CT from the transverse plane of giant cell cancer in the distal end of the left femoral bone (indicated by the crosshair). Maximum standard uptake value, 11.2. CT, computed tomography; PET, positron emission tomography.

sites in 20 patients were analyzed, 4 of which were GCTs that had metastasized to the lung following the recurrence of GCTB in the extremities (Figs. 5 and 6). The aggressiveness of GCTB can differ between individuals, which could cause local destruction and metastasis (15). Previous studies have reported that GCTB metastasizes to the lymph nodes, liver, soft tissue, brain, mediastinum, scalp, kidney and penis (16-19).

Histologically, the tumor consists of osteoclast-like and spindle-shaped multinucleated giant cells (20). These giant cells share the same specific markers as osteoclasts, including tartrate-resistant acid phosphatase (21), cathepsin K (22), carbonic anhydrase II (23), calcitonin receptor (24) and receptor activator of nuclear factor $\kappa$-light-chain-enhancer of activated B cells (25), and are similarly capable of bone resorption. Giant cells are, however, substantially larger than the osteoclasts and contain hundreds of nuclei (26). Previous 
Table I. SUVmax of GCTB in different locations.

SUVmax value

\begin{tabular}{lcccrr} 
GCTB location & Patient no. & Lowest & Highest & Median & Mean \pm SD \\
\hline Femoral bone & 7 & 1.8 & 14.5 & 7.5 & $8.4 \pm 4.6$ \\
Below knee & 8 & 3.9 & 14.4 & 7.8 & $8.3 \pm 3.5$ \\
Spine & 4 & 7.6 & 13.7 & 10.0 & $10.4 \pm 2.7$ \\
Pelvis & 3 & 5.2 & 18.6 & 12.6 & $12.1 \pm 6.7$ \\
Lung & 4 & 4.5 & 10.8 & 9.9 & $8.8 \pm 2.9$ \\
\hline
\end{tabular}

SUVmax, maximum standard uptake value; GCTB, giant cell tumor of the bone; SD, standard deviation.
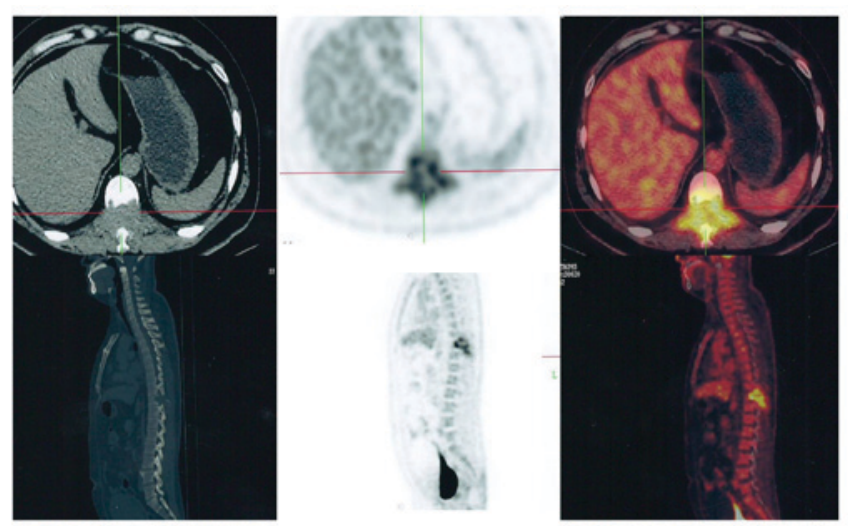

Figure 3. CT, PET and PET/CT images in transverse and sagittal planes of giant cell tumor of the T10 vertebra (indicated by the crosshair). Maximum standard uptake value, 7.6. CT, computed tomography; PET, positron emission tomography.
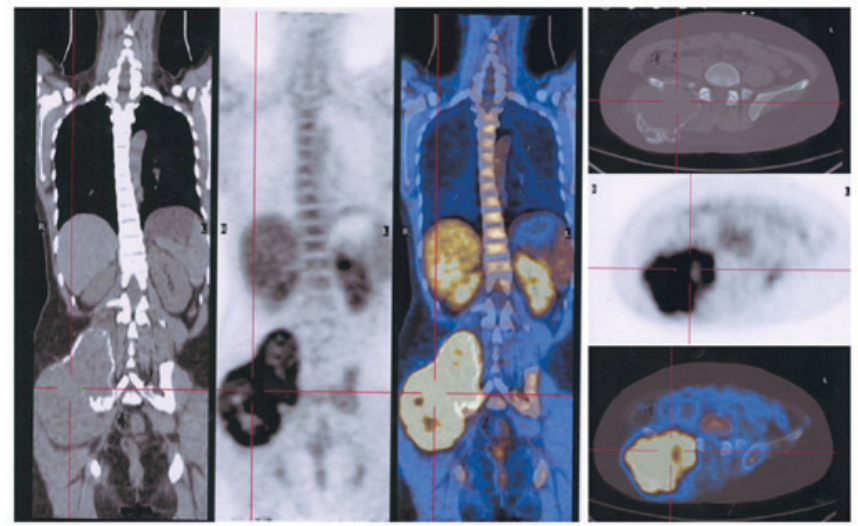

Figure 4. Images from (A) CT, (B) PET and (C) PET/CT from the coronal plane, and (D) CT, (E) PET and (F) PET/CT images from the transverse plane of giant cell tumor of the bone of the right iliac bone (indicated by the crosshair). Maximum standard uptake value, 5.2. CT, computed tomography; PET, positron emission tomography.

studies have provided clinicians with diagnostic genetic markers of GCTB, including tumor proteins 53, 63 and 73, kinectin, nebulin, $\rho$-associated coiled-coil containing protein kinase 1 , and sterile $\alpha$-motif and leucine zipper-containing kinase AZK (27-29).

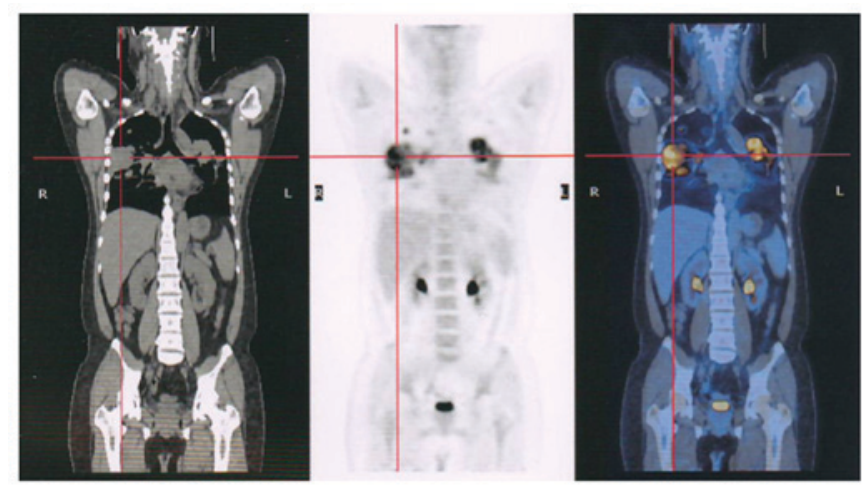

Figure 5. Images from (A) CT, (B) PET and (C) PET/CT from the coronal plane of giant cell tumor of the bone metastasis to the lung (indicated by the crosshair). Maximum standard uptake value, 11.1.

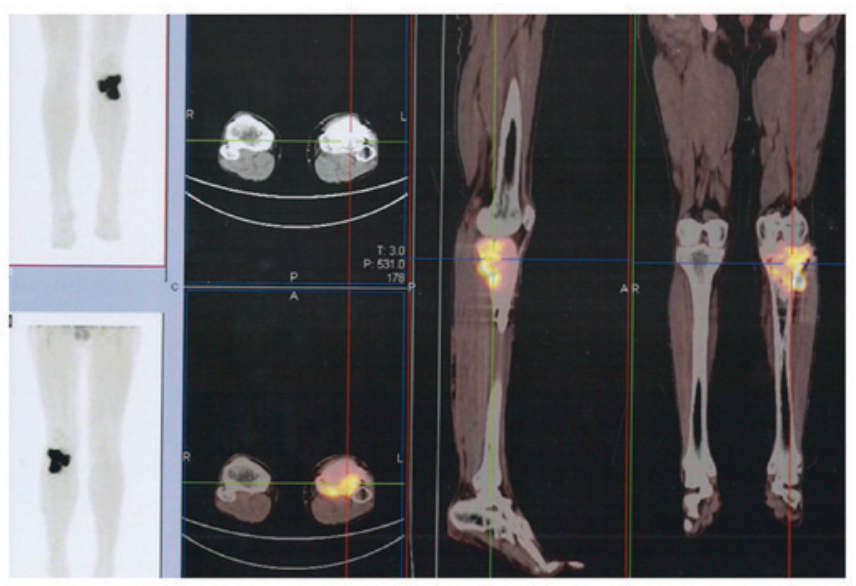

Figure 6. Images from PET/CT in (A) the sagittal and (B) the coronal plane, of recurrent giant cell tumor of the bone in the left proximal tibial bone (indicated by the crosshair). Maximum standard uptake value, 14.4. CT, computed tomography; PET, positron emission tomography.

Unlike the majority of non-malignant tumors, the majority of GCTB lesions in the present study exhibited the intensive uptake of ${ }^{18} \mathrm{~F}$-FDG. This could be explained by the cellular consistency of GCTB. Previous studies have demonstrated that glucose transporter type 1 (GLUT-1) is upregulated in human macrophages $(30,31)$ and that the avidity of ${ }^{18} \mathrm{~F}-\mathrm{FDG}$ for GLUT-1 is positively associated with GLUT-1 overexpression $(32,33)$. 
In a previous study, Hoshi et al suggested that the avidity of ${ }^{18} \mathrm{~F}-\mathrm{FDG}$ was closely associated with strong hexokinase-2 activity in giant and spindle cells (34). It is possible that the high SUVmax of GCTB obtained from the PET/CT scans is a result of GLUT-1 and hexokinase-2 overexpression in macrophages and giant cells in the tumor. The results of the present study suggest that, in order to avoid excessive and unnecessary medical treatment, a diagnosis of GCTB should be considered when PET/CT reveals the presence of a bone lesion with intense ${ }^{18} \mathrm{~F}$-FDG uptake that is suggestive of a high-grade osseous sarcoma.

\section{References}

1. Enneking WF: Musculoskeletal tumor surgery. Churchill Livingstone, New York, NY, 1983.

2. Gong L, Liu W, Sun X, Sajdik C, Tian X, Niu X and Huang X: Histological and clinical characteristics of malignant giant cell tumor of bone. Virchows Arch 460: 327-334, 2012.

3. Feigenberg SJ, Marcus RB Jr, Zlotecki RA, Scarborough MT and Enneking WF: Whole-lung radiotherapy for giant cell tumors of bone with pulmonary metastases. Clin Orthop Relat Res: 202-208, 2002

4. Ropars M, Kaila R, Cannon SR and Briggs TW: Primary giant cell tumours of the digital bones of the hand. J Hand Surg Eur Vol 32: 160-164, 2007.

5. Tian R, Su M, Tian Y, Li F, Li L, Kuang A and Zeng J: Dual-time point PET/CT with F-18 FDG for the differentiation of malignant and benign bone lesions. Skeletal Radiol 38: 451-458, 2009.

6. Lackman RD, Hosalkar HS, Ogilvie CM, Torbert JT and Fox EJ: Intralesional curettage for grades II and III giant cell tumors of bone. Clin Orthop Relat Res 438: 123-127, 2005.

7. Kivioja AH, Blomqvist C, Hietaniemi K, Trovik C, Walloe A, Bauer HC, Jorgensen PH, Bergh P and Follerås G: Cement is recommended in intralesional surgery of giant cell tumors: A Scandinavian Sarcoma Group study of 294 patients followed for a median time of 5 years. Acta Orthop 79: 86-93, 2008.

8. Niu X, Zhang Q, Hao L, Ding Y, Li Y, Xu H and Liu W: Giant Cell Tumor of the Extremity: Retrospective analysis of 621 Chinese patients from one institution. J Bone Joint Surg Am 94: 461-467, 2012.

9. Moon JC, Kim SR, Chung MJ and Lee YC: Multiple pulmonary metastases from giant cell tumor of a hand. Am J Med Sci 343: 171-173, 2012.

10. Osaka S, Sugita H, Osaka E, Yoshida Y, Ryu J, Hemmi A and Suzuki K: Clinical and immunohistochemical characteristics of benign giant cell tumour of bone with pulmonary metastases: Case series. J Orthop Surg (Hong Kong) 12: 55-62, 2004.

11. Kim TS and Park JS: Metastasising recurrent giant cell tumor: A case report. J Korean Bone Joint Tumor Soc 7: 73-79, 2001.

12. Mirra JM: Giant cell tumors. In: Bone tumors: clinical, radiologic and pathologic correlations. Lea and Febiger, Philadelphia, PA, pp941-1020, 1989.

13. Averill RM, Smith RJ and Campbell CJ: Giant cell tumors of the bones of the hand. J Hand Surg Am 5: 39-50, 1980.

14. Balke M, Schremper L, Gebert C, Ahrens H, Streitbuerger A, Koehler G, Hardes J and Gosheger G: Giant cell tumor of bone: Treatment and outcome of 214 cases. J Cancer Res Clin Oncol 134: 969-978, 2008.

15. Takeuchi A, Tsuchiya H, Niu X, Ueda T, Jeon DG, Wang EH, Asavamongkolkul A, Kusuzaki K, Sakayama K and Kang YK: The prognostic factors of recurrent GCT: A cooperative study by the Eastern Asian Musculoskeletal oncology group. J Orthop Sci 16: 196-202, 2011

16. Muheremu A and Niu X: Pulmonary metastasis of giant cell tumor of bones. World J Surg Oncol 12: 261, 2014.
17. Jacopin S, Viehweger E, Glard Y, Launay F, Jouve JL, Bouvier C and Bollini G: Fatal lung metastasis secondary to index finger giant cell tumor in an 8-year-old child. Orthop Traumatol Surg Res 96: 310-313, 2010

18. Kremen TJ Jr, Bernthal NM, Eckardt MA and Eckardt JJ: Giant cell tumor of bone: Are we stratifying results appropriately? Clin Orthop Relat Res 470: 677-683, 2012.

19. Muheremu A, Huang Z and Niu X: Treatment for giant cell tumor of the spine metastasizing to the lung: A report of two cases and a literature review. Oncol Lett 9: 1321-1326, 2015.

20. Werner M: Giant cell tumour of bone: Morphological, biological and histogenetical aspects. Int Orthop 30: 484-489, 2006.

21. Anazawa U, Hanaoka H, Shiraishi T, Morioka H, Morii T and Toyama Y: Similarities between giant cell tumor of bone, giant cell tumor of tendon sheath, and pigmented villonodular synovitis concerning ultrastructural cytochemical features of multinucleated giant cells and mononuclear stromal cells. Ultrastruct Pathol 30: 151-158, 2006.

22. Lindeman JH, Hanemaaijer R, Mulder A, Dijkstra PD, Szuhai K, Bromme D, Verheijen JH and Hogendoorn PC: Cathepsin K is the principal protease in giant cell tumor of bone. Am J Pathol 165: 593-600, 2004.

23. Kotake S, Sato K, Kim KJ, Takahashi N, Udagawa N, Nakamura I, Yamaguchi A, Kishimoto T, Suda T and Kashiwazaki S: Interleukin-6 and soluble interleukin-6 receptors in the synovial fluids from rheumatoid arthritis patients are responsible for osteoclast-like cell formation. J Bone Miner Res 11: 88-95, 1996.

24. Collier FM, Huang WH, Holloway WR, Hodge JM, Gillespie MT, Daniels LL, Zheng MH and Nicholson GC: Osteoclasts from human giant cell tumors of bone lack estrogen receptors. Endocrinology 139: 1258-1267, 1998.

25. Atkins GJ, Kostakis P, Vincent C, Farrugia AN, Houchins JP, Findlay DM, Evdokiou A and Zannettino AC: RANK expression as a cell surface marker of human osteoclast precursors in peripheral blood, bone marrow, and giant cell tumors of bone. J Bone Miner Res 21: 1339-1349, 2006.

26. Balke M, Campanacci L, Gebert C, Picci P, Gibbons M, Taylor R, Hogendoorn P, Kroep J, Wass J and Athanasou N: Bisphosphonate treatment of aggressive primary, recurrent and metastatic giant cell tumour of bone. BMC Cancer 10: 462, 2010.

27. Cowan RW and Singh G: Giant cell tumor of bone: A basic science perspective. Bone 52: 238-246, 2013.

28. Graziano V and De Laurenzi V: Role of p63 in cancer development. Biochim Biophys Acta 1816: 57-66, 2011.

29. Babeto E, Conceição AL, Valsechi MC, Peitl Junior P, de Campos Zuccari DA, de Lima LG, Bonilha JL, de Freitas Calmon M, Cordeiro JA and Rahal P: Differentially expressed genes in giant cell tumor of bone. Virchows Arch 458: 467-476, 2011.

30. Fu Y, Maianu L, Melbert BR and Garvey WT: Facilitative glucose transporter gene expression in human lymphocytes, monocytes, and macrophages: A role for GLUT isoforms 1, 3 , and 5 in the immune response and foam cell formation. Blood Cells Mol Dis 32: 182-190, 2004.

31. Malide D, Davies-Hill TM, Levine M and Simpson IA: Distinct localization of GLUT-1, -3 and -5 in human monocyte-derived macrophages: Effects of cell activation. Am J Physiol 274: E516-E526, 1998.

32. Chung JH, Cho KJ, Lee SS, Baek HJ, Park JH, Cheon GJ, Choi CW and Lim SM: Overexpression of Glut1 in lymphoid follicles correlates with false-positive (18)F-FDG PET results in lung cancer staging. J Nucl Med 45: 999-1003, 2004.

33. Horiuchi C, Tsukuda M, Taguchi T, Ishiguro Y, Okudera K and Inoue T: Correlation between FDG-PET findings and GLUT1 expression in salivary gland pleomorphic adenomas. Ann Nucl Med 22: 693-698, 2008.

34. Hoshi M, Takada J, Oebisu N, Hata K, Ieguchi M and Nakamura H: Overexpression of hexokinase-2 in giant cell tumor of bone is associated with false positive in bone tumor on FDG-PET/CT. Arch Orthop Trauma Surg 132: 1561-1568, 2012. 